Rev Esp Casos Clin Med Intern (RECCMI). 2021 (Abril); 6(1): 19-22

\title{
Hematoma retroperitoneal espontáneo en paciente con SARS-CoV-2
}

\author{
Ana González-Torre-González, Tamara Gómez-Traveso, Raquel Jaso-Tejera, Elena Casuso-Sáenz, Nuria Díez-Herrán \\ Servicio de Medicina Interna, Hospital Comarcal de Laredo, Laredo, Cantabria, España
}

Recibido: 15/11/2020

Aceptado: 14/01/2021

En línea: 30/04/2021

Citar como: González-Torre-González A, Gómez-Traveso T, Jaso-Tejera R, Casuso-Sáenz E. Díez-Herrán N. Hematoma retroperitoneal espontáneo en paciente con SARS-CoV-2. Rev Esp Casos Clin Med Intern (RECCMI). 2021 (abril); 6(1): 19-22. doi: 10.32818/reccmi.a6n1a7.

Cite this as: González-Torre-González A, Gómez-Traveso T, Jaso-Tejera R, Casuso-Sáenz E. Díez-Herrán N. Spontaneous retroperitoneal hematoma in a patient with SARS-COV-2. Rev Esp Casos Clin Med Intern (RECCMI). 2021 (April); 6(1): 19-22. doi: 10.32818/reccmi.a6n1a7.

Autor para correspondencia: Ana González-Torre. ana_gtorre@hotmail.com

\section{Palabras clave}

$\triangleright$ SARS-COV-2

$\triangleright$ Heparina

$\triangleright$ Hematoma retroperitoneal

\begin{tabular}{l} 
Keywords \\
\hline SARS-CoV-2 \\
$\triangleright$ Heparin \\
$\triangleright$ Retroperitoneal hematoma
\end{tabular}

\section{Resumen}

La asociación del hematoma retroperitoneal y el tratamiento anticoagulante se ha descrito en pocas ocasiones. Dado que el tratamiento con heparina se ha introducido como parte de los protocolos de tratamiento en pacientes con SARS-CoV-2, se ha realizado una revisión de los dos únicos hematomas retroperitoneales espontáneos que han tenido lugar en nuestro hospital. Estos pacientes ingresaron por neumonía asociada a COVID-19 durante el estado de alarma y recibían heparina de bajo peso molecular a dosis anticoagulantes.

Abstract
The association of retroperitoneal hematoma and anticoagulant treatment has been described in a few cases.
Since heparin treatment has been introduced as part of the treatment protocols in patients with Sars-CoV-2,
a review of only two spontaneous retroperitoneal hematomas in patients admitted to our hospital. These pa-
tients with associated pneumonia to COVID-19 during the alarm state received low molecular weight heparin
at anticoagulant doses.

\section{Puntos destacados}

$\triangleright$ Evaluar factores de riesgo, criterios clínicos y antecedentes trombóticos familiares y personales a la hora de anticoagular a pacientes ingresados por SARS-CoV-2.

$\triangleright$ Es fundamental que los esquemas de tromboprofilaxis se sustenten en ensayos clínicos bien diseñados para disminuir complicaciones.

\section{Introducción}

Aunque se desconoce la incidencia de enfermedad trombótica en pacientes con COVID-19, se sabe que sufren un estado inflamatorio que condiciona un alto riesgo trombótico debido a cambios protrombóticos, daño endotelial y reducción del flujo venoso por el reposo prolongado. Por ello, estos pacientes son candidatos a recibir tromboprofilaxis con heparina de bajo peso molecular (HBPM) y/o medios físicos en función del riesgo hemorrágico.

Este tratamiento con heparina se ha introducido dentro de los protocolos de tratamiento del SARS-CoV-2 y ha mostrado resultados prometedores al comparar la mortalidad entre usuarios y no usuarios de la misma. Sin embargo, a la hora de pautarla, hay que tener en cuenta la existencia de posibles interacciones y riesgo de sangrado'. Su prescripción conlleva dudas en la práctica clínica dado que hay poca información sobre cómo abordar el riesgo trombótico, la coagulopatía y el tratamiento anticoagulante de estos pacientes².
El hematoma retroperitoneal espontáneo (HRE) es una entidad poco frecuente y con una evolución potencialmente mortal. El espacio retroperitoneal es un espacio virtual que puede convertirse en un reservorio de sangre, que, habitualmente, se traduce en una falta inicial de sintomatología y, por tanto, en un retraso en el diagnóstico. Generalmente se relaciona con a patología estructural de los órganos retroperitoneales y al uso de medicamentos anticoagulantes asociados o no a antiagregantes plaquetarios.

\section{Caso clínico 1}

\section{Antecedentes personales}

Varón de 83 años. Antecedentes de HTA, FA permanente y portador de marcapasos por FA bloqueada. Toma tratamiento con furosemida, acenocumarol y valsartán. Ingresa por cuadro de malestar general de una semana de evolución, anorexia, tos seca y febrícula.

\section{Exploración física}

Tensión arterial: 191/81 mmHg; frecuencia cardíaca: 64 lpm; saturación de oxígeno basal: 96\%; frecuencia respiratoria: 25 rpm. Taquipneico. Auscultación cardíaca: tonos arrítmicos sin soplos. Auscultación pulmonar: hipofonesis generalizada. 
González-Torre-González A, Gómez-TravesoT, Jaso-Tejera R, Casuso-Sáenz E, Díez-Herrán N. Hematoma retroperitoneal espontáneo en paciente con SARS-CoV-2

\section{Pruebas complementarias}

- Analítica: hemograma: normal. INR: 2,84 (0,8-1,28), A. Protrombina: 24\% (70120), FG: $49 \mathrm{~mL} / \mathrm{min} / 1,73 \mathrm{~m}^{2}$ (> 60); LDH: $305 \mathrm{U} / \mathrm{L}$ (120-246); CK: $227 \mathrm{U} / \mathrm{L}$ (46-171); troponina: $61 \mathrm{ng} / \mathrm{L}(<40), \mathrm{PCR}: 7,6 \mathrm{mg} / \mathrm{dL}(<0,5)$, y el resto, normal. Gasometría arterial: $\mathrm{pCO}_{2}: 28 \mathrm{mmHg}(35-48) ; \mathrm{pO}_{2}: 60$ mmHg (80-108), bicarbonato: $21,8 \mathrm{mmol} / \mathrm{L}(21,2-28.3)$.

- PCR SARS-CoV-2 positiva.

- Radiografía de tórax: infiltrado alveolointersticial difuso bilateral (Figura 1).

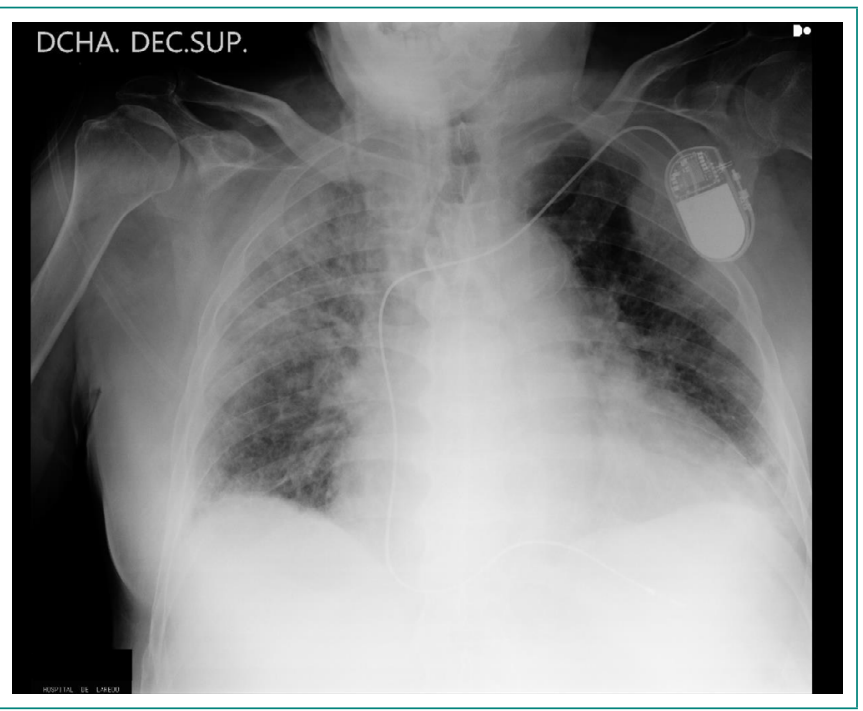

Figura 1. Radiografía de tórax decúbito supino. Infiltrado alveolointersticial difuso bilateral.

\section{Evolución}

Presenta una evolución tórpida y precisa tratamiento para la enfermedad principal y varias complicaciones como el fracaso respiratorio hipoxémico, insufi- ciencia renal aguda, insuficiencia cardíaca, hiperreactividad bronquial y sobreinfección bacteriana. En los controles analíticos periódicos se objetivó elevación progresiva de reactantes de fase aguda y deterioro de la función renal.

Recibió oxigenoterapia, piperacilina/tazobactam, metilprednisolona 40 mg cada 12 horas, hidroxicloroquina, broncodilatadores, acetilcisteína, diuréticos y anticoagulación con HBPM ajustada a función renal (60mg/12 horas) según el protocolo vigente en ese momento en nuestro hospital. Posteriormente, presentó una disminución brusca del nivel de conciencia e inestabilidad hemodinámica, con uso de la musculatura accesoria y dolor abdominal.

Analíticamente se objetivó una caída de tres puntos de la hemoglobina y un empeoramiento de la fórmula leucocitaria, así como una acidosis metabólica. Se solicitó TAC abdominal (Figura 2) observándose un engrosamiento del músculo psoas ilíaco derecho hasta región inguinal en relación con hematoma.

Sufre shock hipovolémico sin respuesta a tratamiento con fluidoterapia y aminas vasoactivas que le lleva al fallecimiento.

\section{Caso clínico 2}

\section{Antecedentes personales}

Mujer de 74 años. Antecedentes de HTA, dislipemia y asma persistente grave eosinofílico. Toma tratamiento con ezetimiba, azitromicina, monteleukast, tiotropio y budesonida/formoterol.

Ingresa por cuadro de una semana de evolución consistente en fiebre, tos con expectoración verdosa y disnea.

\section{Exploración física}

Tensión arterial: 143/72 mmHg; frecuencia cardíaca: 102 lpm; saturación de oxígeno basal: 96\%; frecuencia respiratoria: 18 rpm. Auscultación pulmonar: crepitantes en base derecha.

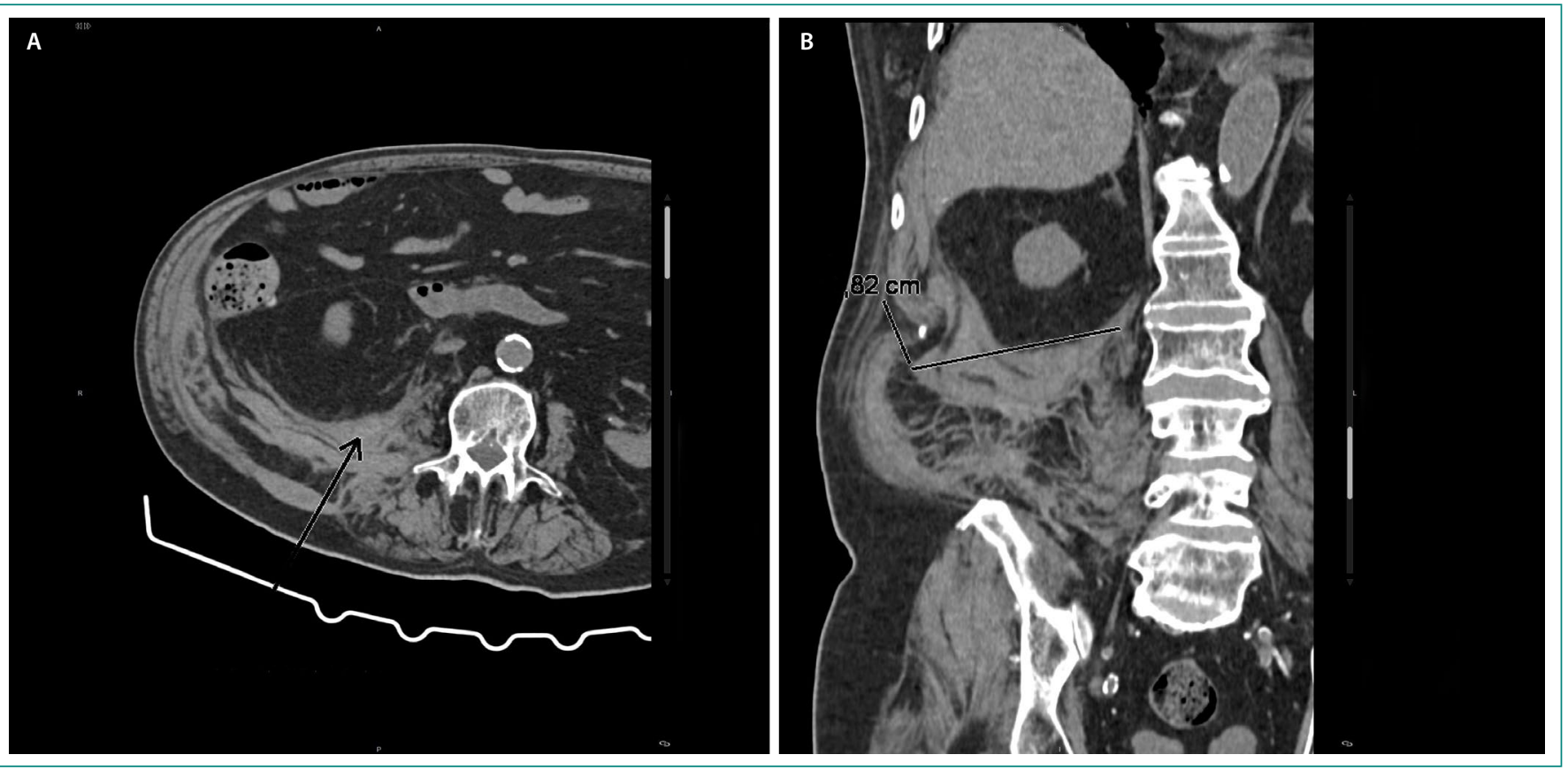

Figura 2. TAC abdominal sin contraste: hematoma retroperitoneal derecha . A. Corte axial. B. Corte coronal. 


\section{Pruebas complementarias}

- Analítica: Leucocitos: $15 \times 103 \mu \mathrm{L}$ (3.000-10.000), 80,7\% N (42-75), 10,4\% L (20-50), hemoglobina: 11,4 g/dL (13-18), y el resto es normal. Dímero D: $1.492 \mathrm{ng} / \mathrm{mL}$ (0-500), FG: $42 \mathrm{ml} / \mathrm{min} / 1,73 \mathrm{~m}^{2}(>60) ; \mathrm{PCR}: 13,5 \mathrm{mg} / \mathrm{dL}(<0,5)$, y el resto, normal. Gasometría: $\mathrm{pCO}_{2}: 39$ mmHg (35-45), $\mathrm{pO}_{2}: 62$ mmHg (80108) ; bicarbonato: $27 \mathrm{mmol} / \mathrm{L}(21,2-28,3)$

- PCR SARS-CoV-2 positiva

- Radiografía de tórax: aumento de densidad en hemitórax derecho y opacidades parcheadas periféricas (Figura 3).

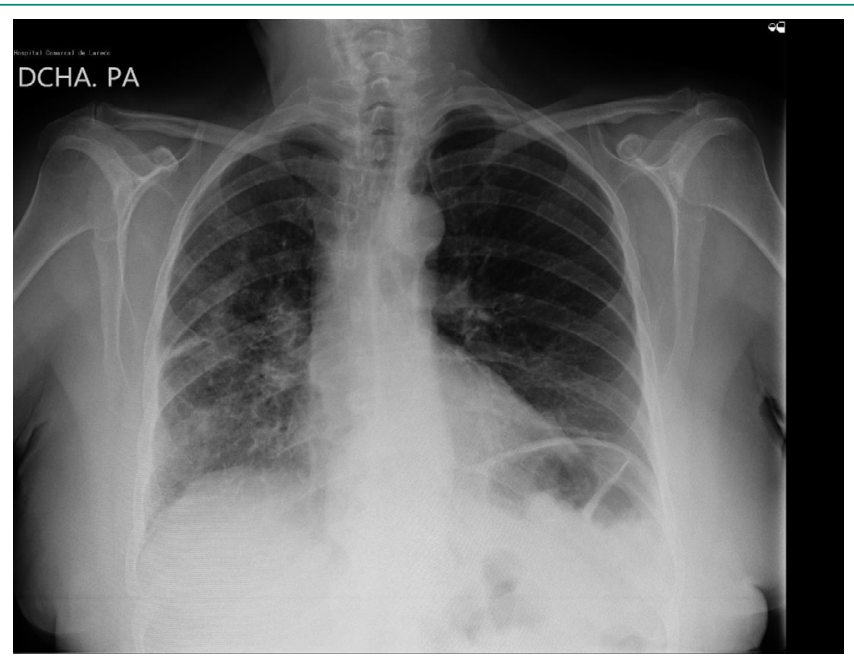

Figura 3. Radiografía de tórax infiltrado en hemitórax derecho y opacidades periféricas.

\section{Evolución}

Se inicia oxigenoterapia, ceftriaxona, azitromicina, metilprednisolona $40 \mathrm{mg}$ cada 12 horas, hidroxicloroquina, así como HBPM a dosis de 60 mg cada 12 horas. Tras conseguir estabilidad y mejoría clínica, comienza una semana después con marcada palidez mucocutanea, oliguria e hipotensión. En la exploración abdominal llama la atención la ausencia de ruidos hidroaéreos. Se realiza TAC abdominal (Figura 4) donde se objetiva colección retroperitoneal izquierda adyacente al psoas que se extiende hasta fosa ilíaca.

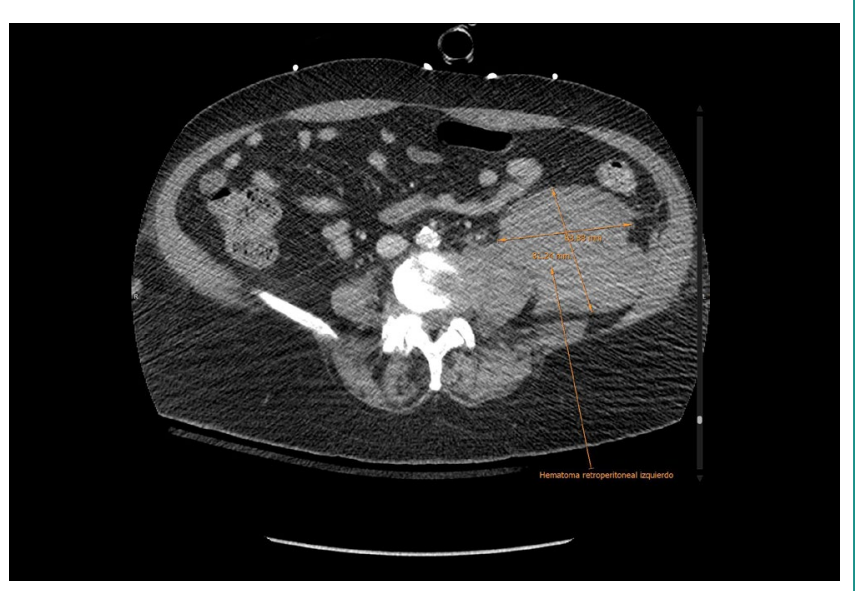

Figura 4. TAC abdominal sin contraste. Hematoma retroperitoneal izquierdo.
Se traslada a la unidad de cuidados intensivos (UCI) procediéndose a la estabilización hemodinámica con transfusiones y corrección de la anticoagulación. Precisa ventilación. mecánica y nutrición parenteral por íleo. Finalmente evoluciona favorablemente.

\section{Discusión y conclusión}

La asociación del HRE y el tratamiento anticoagulante se ha descrito en pocos casos, y en muchos de ellos con desenlace fatal ${ }^{3}$. Las HBPM han demostrado ser efectivas y seguras en el tratamiento de la trombosis venosa profunda, el tromboembolismo pulmonar y en la profilaxis de fenómenos tromboembólicos ${ }^{4}$. Producen un efecto anticogulante predecible por su biodisponibilidad, mayor vida media y cinética de aclaramiento, por lo que no suele ser necesaria su monitorización.

La incidencia de complicaciones hemorrágicas asociadas a su uso no se conoce con exactitud ya que solo se han descrito casos aislados de hemorragia intrahepática, hematomas del psoas, pared abdominal, retroperitoneal y epidural. La bibliografía presenta diversas causas de sangrado; en nuestros pacientes fue la edad y la disfunción renal los dos factores que pudieron haber contribuido al desarrollo del HRE. Aunque la incidencia de HRE es baja y la de eventos trombóticos en pacientes hospitalizados por infección por SARS-CoV-2 es elevada, se debe evaluar la necesidad de anticoagular teniendo en cuenta los factores de riesgo, los criterios clínicos y los antecedentes trombóticos familiares y personales, así como las interacciones con otros tratamientos para la infección viral. Así se logrará disminuir todo lo posible el riesgo de sangrado, sobre todo, en pacientes similares a los nuestros, con edad avanzada o deterioro de la función renal.

Desde el inicio de la pandemia hemos ido perfeccionando el tratamiento implantado para tratar a pacientes hospitalizados por SARS-CoV-2, lo que nos ha permitido unificar y delimitar criterios y pautas de anticoagulación en función de los factores de riesgo, consiguiendo disminuir el número de complicaciones y mejorando la supervivencia (Organización Mundial de la Salud, Sociedad Internacional de Hemostasia y Trombosis, Padua, IMPROVE) $)^{5}$. Por lo tanto, en ausencia de datos fiables sobre la tasa real de eventos trombóticos y hemorrágicos en los pacientes con COVID-19, los cambios en los esquemas habituales de tromboprofilaxis deberían sustentarse en los resultados de ensayos clínicos bien diseñados que se están realizando de forma progresiva ${ }^{5}$.

Además, hay que tener en cuenta que los pacientes con COVID-19 pueden presentar otras complicaciones al margen de la propia infección viral. La aparición de nuevos síntomas o signos nos debe hacer sospechar de la existencia de otros problemas concomitantes, incluso derivados de la iatrogenia. Si se detectan precozmente, se pueden evitar situaciones como las de nuestros pacientes, por lo que conviene realizar una monitorización analítica y el ajuste de los tratamientos a cada situación clínica ${ }^{6}$.

\section{Bibliografía}

1. Tang N, Bai H, Chen X, Gong J, Li D, Sun Z. Anticoagulant treatment is associated with decreased mortality in severe coronavirus disease 2019 patients with coagulopathy. J Thromb Haemost. 2020; 18(5): 1094-1099. doi: 10.1111/jth.14817.

2. Bikdeli B, Madhavan MV, Jimenez D, Chuich T, Dreyfus I, Driggin E, et al.; Global COVID-19 Thrombosis Collaborative Group, Endorsed by the ISTH, NATF, ESVM, and the IUA, Supported by the ESC Working Group on Pulmonary Circulation and Right Ventricular Function. COVID-19 and Thrombotic or Thromboembolic Disease: Implications for Prevention, Antithrombotic 
Therapy, and Follow-Up: JACC State-of-the-Art Review. J Am Coll Cardiol. 2020; 75(23): 2950-2973. doi: 10.1016/j.jacc.2020.04.031.

3. Salemis NS, Oikonomakis I, Lagoudianakis E, Boubousis G, Tsakalakis C, Sourlas $\mathrm{S}$, et al. Enoxaparin-induced spontaneous massive retroperitoneal hematoma with fatal outcome. Am J Emerg Med. 2014; 32(12): 1559.e1-3. doi 10.1016/j.ajem.2014.05.026

4. Daliakopoulos SI, Bairaktaris A, Papadimitriou D, Pappas P. Gigantic retroperitoneal hematoma as a complication of anticoagulation therapy with heparin in therapeutic doses: a case report. J Med Case Rep. 2008; 2: 162 doi: 10.1186/1752-1947-2-162.
5. Vivas D, Roldán V, Esteve-Pastor MA, Roldán I, Tello-Montoliu A, Ruiz-Nodar JM, et al.; Revisores expertos. Recomendaciones sobre el tratamiento antitrombótico durante la pandemia COVID-19. Posicionamiento del Grupo de Trabajo de Trombosis Cardiovascular de la Sociedad Española de Cardiología. Rev Esp Cardiol.2020; 73(9): 749-757. doi: 10.1016/j.recesp.2020.04.006.

6. Wang T, Du Z, Zhu F, Cao Z, An Y, Gao Y, et al. Comorbidities and multi-organ injuries in the treatment of COVID-19. Lancet. 2020; 395(10228): e52. doi: 10.1016/S0140-6736(20)30558-4. 